\title{
BAJO SOSPECHA. Debates urgentes sobre las clases trabajadoras en la Argentina
}

\author{
Programa de Antropología en co-labor. (2019). Bajo Sospecha. Debates urgentes sobre las Clases \\ trabajadoras en la Argentina. Ciudad de Buenos Aires: CALLAO Cooperativa Cultural. 192 pp.
}

\section{Nashieli Rangel Loera}

\author{
Departamento de Antropología-Unicamp. Brasil. \\ Fellow 2020-2021 del Institut d'Études Avancées de Nantes. Francia. \\ Grant 2020/11197-3, São Paulo Research Foundation (FAPESP). \\ (iD) https://orcid.org/oooo-0003-4728-1017 \\ Correo electrónico: NASHIELI.Loera@iea-nantes.fr
}

\section{Recibido:}

16 de febrero de 2021

Aceptado:

2 de agosto de 2021

doi: 10.34096/runa.v42i2.9817

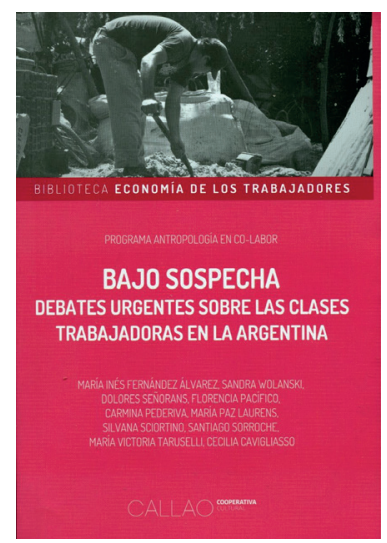

En 1944, el economista Karl Polanyi en su clásico “La gran transformación”"1 nos alertaba que aquello que llamamos comúnmente como el "sistema económico" no es algo que pueda ser visto separado de la vida social. Para Polanyi sería necesario recuperar algo que parecemos haber olvidado con nuestra supuesta modernidad: el significado sustantivo de "economía", esa búsqueda por la reproducción material de la propia vida. Una acepción que nos recuerda el propio sentido etimológico de la palabra y que remete a una combinación de oikos -casa o morada- y nomos - ley, gobierno o administración, o némein, como la acción de gestionar o distribuir. En una publicación reciente, Fernández y Perelman $(2020)^{2}$ revitalizan esta discusión clásica y la amplían poniendo en diálogo una serie de trabajos etnográficos que se proponen "repensar la economía" a partir de una mirada hacía las maneras múltiples y creativas en que diversos sujetos, en diferentes contextos sociales y nacionales buscan modos de sostener y de "ganarse la vida". BAJO SOSPECHA es una linda publicación colectiva acerca de y con clases trabajadoras en la Argentina que se incluye también en este debate, y en sus casi 200 páginas se nos muestra como diariamente trabajadores y trabajadoras de las llamadas clases populares ponen en marcha los engranajes, o, mejor dicho, en palabras de Silvia -vendedora ambulante del tren y una de las protagonistas de esta publicación- "las refacciones sociales" de la vida de la economía argentina, de esa que es la casa de casi 45 millones de personas.

En bajo sospecha hay un claro recorte político-temporal, el gobierno Macri y sus efectos sociales, un momento, como se menciona en la introducción "de deterioro de las condiciones generales de la vida de los y las argentinas por un recrudecimiento de las acciones represivas, y por una serie de medidas económicas orientadas a la distribución regresiva del ingreso, medidas que afectaron particularmente a las clases trabajadoras".

En ese contexto palabras como mafia, esclavos, vagos, planeros, violentos ocupan los titulares de la prensa, y términos como chorros, cazadores de planes sociales,

\section{Polanyi, Karl. (1989). La gran transformación. Crítica del liberalismo económico. Madrid: Quipu editorial.}

2. Dossier "Perspectivas antropológicas sobre las formas de (ganarse la) vida". Cuadernos de Antropología social n. 51, 2020. DOI: 10.34096 cas. 1518270

Nota del Autor: Una versión anterior de este texto fue preparada como presentación de la último congreso de la Asociación latinoamericana de Antropología $(\mathrm{ALA})$, realizado en noviembre de 2020. publicación aquí reseñada, en el 
Sigaud, Lygia. (2013). O mundo desmagicizado. Revista Mana 19 (3).

4. Fassin, Didier. (2015). A companion to moral Anthropology. UK: Willey Blackwell. son repetidos por el sentido común poniendo justamente BAJO SOSPECHA a estos trabajadores, y como en un juego metonímico-moral, por añadidura, también son sospechosos y moralmente etiquetados los espacios de habitación y de trabajo que ocupan. De esta manera, todo un ensamblaje de personas, lugares y prácticas son vistos con desconfianza, con temor, son puestos bajo duda, y muchas veces, es esta "sospecha" la que marca el tono de políticas públicas o de acciones de gobierno dirigidas a las clases trabajadoras. Esta apreciación valorativa del mundo social que se expresa en el lenguaje es terreno fértil para el trabajo antropológico (Sigaud, 2013). ${ }^{3}$ Didier Fassin $(2015)^{4}$ en la introducción a la compilación "A companion to moral Anthropology", se inspira en toda una genealogía de autores, que va de Durkheim a Weber, Malinowski o inclusive Foucault y enfatiza la actualidad de una agenda de estudios etnográficos que interrogan las categorías morales a través de las cuales no solo aprendemos el mundo social sino también lo recriamos, evidenciando así los vínculos existentes y no siempre evidentes entre moral y política.

En BAJO SOSPECHA, las autoras (y digo autoras pues es casi enteramente un libro escrito por mujeres) no solo interrogan estas afirmaciones de sentido común acerca de las clases trabajadoras en la Argentina, sino que asumen como desafío metodológico el "dejarse encantar" por determinadas visiones de mundo, es decir "compartir y tomar como propios para el análisis, determinadas lecturas y posicionamientos políticos" de las organizaciones de trabajadores y trabajadoras, y a partir de este ejercicio de reflexión colaborativa nos muestran la compleja trama de relaciones producidas cotidianamente en los barrios, en las casas, en los talleres, en las familias de los y las trabajadoras que permiten el sostén de la vida, vidas que dependen unas de las otras, y que en las palabras de la organizadora de esta publicación, María Inés Fernández: "mantienen obligaciones recíprocas, no por ello simétricas". A las marcas estigmatizantes y generalizantes de la sospecha los y las trabajadoras contraponen otras, las suyas propias, y en este proceso, el trabajo, aquello a lo que dedican tanto de sí es sin duda, también, lo que las produce.

Como nos describe la antropóloga María Inés Fernández en el primer capítulo del libro, entre las vendedoras ambulantes del tren, como Silvia, es en el esfuerzo cotidiano para no desaparecer que producen diariamente formas de ser vistas, de ganarse la vida, pero al mismo tiempo, el trabajo en el tren también se porta en el cuerpo, en las venas, en el nombre y parece extensible a generaciones familiares, que a partir del tren pueden también heredar una vida mejor. Ya en un barrio Quom de la ciudad de Rosario, el esfuerzo cotidiano del dirigente indígena Osvaldo y de las familias que él representa, es también el de aparecer, pero no de cualquier manera, se niegan a ser folclorizados. Su lucha cotidiana por existir en ese lugar, como así lo describe María Victoria Taruselli en el noveno capítulo, no pasa por demostrar autenticidad, como lo quiere el sentido común, sino por un "trabajo territorial" que implica toda una compleja actividad de organización y un conocimiento particular sobre el barrio y sobre lo que vecinos y vecinas necesitan. Es en este proceso de producción de trabajo territorial que dirigentes como Osvaldo también se producen políticamente. El trabajo activa, produce la participación política pero también la vida política de dirigente puede volverse un trabajo. Ese es también el caso de sindicalistas de la telefonía, como lo describe Sandra Wolanski en el segundo capítulo. El know how de la lucha cotidiana para proteger la estabilidad de los y las trabajadoras telefónicas no es algo que se aprenda de la noche a la mañana. Saber negociar, crear alianzas, unidad, requiere una serie de habilidades sociales que muchas veces se aprenden en el seno familiar, 
y es así como jóvenes hijos, sobrinos, ahijados, conocidos de activistas de la lucha sindical se integran a la larga genealogía sindicalista, un mundo social en donde la "continuidad" es un valor.

"Apoyarse en la familia y los vínculos con paisanos constituyen un modo de construir una forma de trabajo vivenciada como autonomía o independiente" como nos dice Dolores Señorans sobre el cotidiano de los trabajadores y trabajadoras costureras, paraguayos y bolivianos instalados en Buenos Aires. Es produciendo el trabajo como costureros y costureras que también se produce casa, un techo donde vivir con la familia. Como lo demuestran numerosos trabajos etnográficos sobre los procesos migratorios en diversos contextos nacionales, los vínculos previos existentes en las ciudades de destino son fundamentales para la instalación y reconversión de actividad o trabajo y todo lo que implica una adaptación al nuevo lugar. En este proceso, inclusive se percibe que es necesario "preparar el cuerpo" como le describe una interlocutora a la antropóloga. En la búsqueda por "cambiar de vida" se aprenden nuevas profesiones, se van tejiendo también organizaciones y se pone en marcha todo un engranaje particular para la producción de derechos y de ciudadanía.

Como nos lo describe Santiago Sorroche en el octavo capítulo, el trabajo también implica creatividad, es invención. Es así como Nancy, una joven integrante de una cooperativa de cartoneros define su actividad. Es también en este proceso de invención de su propia fuente de trabajo que se despliegan algo más que circuitos de recolección en el caso de los y las cartoneras, o algo más que esfuerzos personales o libertad individual, como también nos lo dice en uno de los capítulos la antropóloga Carmina Pederiva, cuando describe el trabajo que hace Norma, vendiendo sus golosinas en la feria, una actividad y todo un esfuerzo colectivo que integra relaciones de afecto y de ayuda mutua, difícilmente resumible a un discurso del emprendedurismo, como quiere un gobierno neoliberal. Es en ese proceso creativo de producirse colectivamente como trabajadores y trabajadoras que se mejoran condiciones de vida.

Esta invención constante tiene la potencia también de crear espacios de cuidado locales como guarderías o escuelas, pero también otros, más amplios espacialmente, como el propio barrio. "Rutinas, calles, parientes, conocidos" como se describe en el rap de jóvenes Quom del barrio Las Quintas, etnografiado en el séptimo capítulo por Silvana Sciortino, conforman el foco de lo que la antropóloga llama de "geografías de cuidado", acciones producidas cotidianamente por migrantes chaqueños que se empeñan colectivamente en hacer, de ese espacio, un lugar propio. Ya en el caso de villa banana, un barrio periférico de la ciudad de Rosario, presentado en el capítulo de Cecilia Cavigliaso, el cuidado, como trabajo, y el trabajo de cuidado se fueron produciendo como tarea central de organizaciones del barrio y adquieren un sentido amplio, pues como nos dice la autora "abarca la vida en su totalidad e implica construir colectivamente alternativas para hacer frente a las distintas violencias que permean la cotidianidad de los habitantes del barrio".

Parece ser que cuidar, producir casa, escuelas, barrios, producirse en cuanto trabajadores y trabajadoras, defender derechos conquistados, representar, y ganarse la vida para sí y para sus próximos es un conjunto que necesita de toda una compleja red de personas, esfuerzos y de relaciones, muy lejos del "facilismo" expresado por Macri, como nos describe Florencia Pacífico en el cuarto capítulo del libro. Este entramado de vinculaciones "de amistad, afectivas, familiares y políticas" como defiende Paz Laurens en el sexto capítulo, muchas veces puede ser el parteaguas, aquello que cambia la vida a alguien 
5. Fernández Álvarez, María Inés. (2016). Hacer juntos(as). Dinámicas, contornos y relieves de la política colectiva. Buenos Aires: Biblos.

6. Sahlins, Marshal. (2013). What Kinship is - and is not. Chicago: University of Chicago Press. que pasó por la experiencia de encarcelamiento, por ejemplo. Para los "liberados" la propia experiencia de trabajo produciendo cooperativa es lo que abre el camino a otros en situación semejante, y también se torna muchas veces el propio sentido de su vida fuera de la cárcel. "La salida, para ellos, es siempre colectiva".

Tal vez el término que mejor describe este conjunto de acciones variadas y producciones sociales que se hacen posible a partir de la actividad, del trabajo que surge de las cooperativas de la Economía popular sea el de "Refacciones sociales" como nos describe Florencia Pacífico, pues no se trata solo de hacer, implica crear. En BAJO SOSPECHA el trabajo no es un término vacío, muy por el contrario, es continuamente alimentado y producido cotidianamente por vendedoras ambulantes, cartoneros, dirigentes sindicales e indígenas, por costureras, por liberados y tantos otros y otras trabajadoras que ponen en marcha la Economía argentina. Pero el trabajo, en este conjunto etnográfico es también lo que las autoras y el autor consideran un "profundo compromiso" "con quienes impulsan, sostienen, participan o simplemente se vinculan a las organizaciones".

El compromiso como una categoría de la práctica que conecta el trabajo antropológico de este conjunto de autoras, al de las personas involucradas en las organizaciones y cooperativas de la Economía popular argentina ya había sido abordado en otro trabajo y formulado analíticamente como un "Hacer juntos" (Fernández, 2016), ${ }^{5}$ una práctica colaborativa y una forma de construir conocimiento en conjunto y en su transcurrir. Así, el compromiso, como una forma de "hacer juntos" tiene como base el mutuo aprendizaje y una relación de largo plazo, proceso también en el que se produce mutualidad. En las palabras del antropólogo Marshal Sahlins, mutualidad como "personas que participan intrínsicamente en la existencia del otro, que están co-presentes uno en el otro, que tienen un involucramiento activo con relación al otro" (2013:21). ${ }^{6}$

De esta manera, esta publicación colectiva es fruto de un trabajo prolongado y de los vínculos producidos por un equipo de investigación consolidado y dirigido por María Inés Fernández Álvarez, conformado por antropólogas y un antropólogo ya formados y en formación que acumulan años de experiencia y estudio entre los llamados "sectores populares" en la Argentina y sus dinámicas de organización y prácticas políticas.

Finalizo entonces invitando a la lectura cuidadosa de este trabajo que se organiza en una introducción y diez capítulos. Este conjunto parte de una reflexión antropológica, pero construye la posibilidad de un "camino compartido", ya sea con otros especialistas de las ciencias sociales, de la economía, de la política, pero también con un público más amplio interesado en la actividad de las clases trabajadoras y en su contribución para la producción de conocimiento sobre el mundo social. Finalmente, esta obra colaborativa puede ser sin duda una fuente de inspiración y reconocimiento para las propias organizaciones de la Economía Popular de Argentina, y un medio de continuar construyendo "puentes" entre el trabajo académico y aquellos y aquellas que "bajo sospecha", ponen en marcha la vida económica de todo un país. 